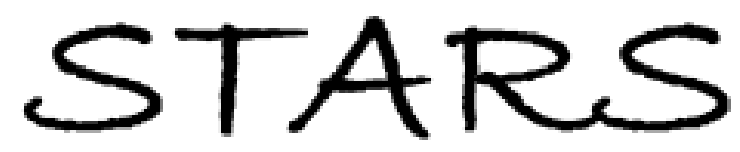

University of Central Florida

STARS

$1-1-2012$

\title{
Non-Erotic Cognitive Distractions During Sexual Activity in Sexual Minority and Heterosexual Young Adults
}

Katharine Lacefield

University of Central Florida

Charles Negy

University of Central Florida

Find similar works at: https://stars.library.ucf.edu/facultybib2010 University of Central Florida Libraries http://library.ucf.edu

This Article is brought to you for free and open access by the Faculty Bibliography at STARS. It has been accepted for inclusion in Faculty Bibliography 2010 s by an authorized administrator of STARS. For more information, please contact STARS@ucf.edu.

\section{Recommended Citation}

Lacefield, Katharine and Negy, Charles, "Non-Erotic Cognitive Distractions During Sexual Activity in Sexual Minority and Heterosexual Young Adults" (2012). Faculty Bibliography 2010s. 2897.

https://stars.library.ucf.edu/facultybib2010/2897

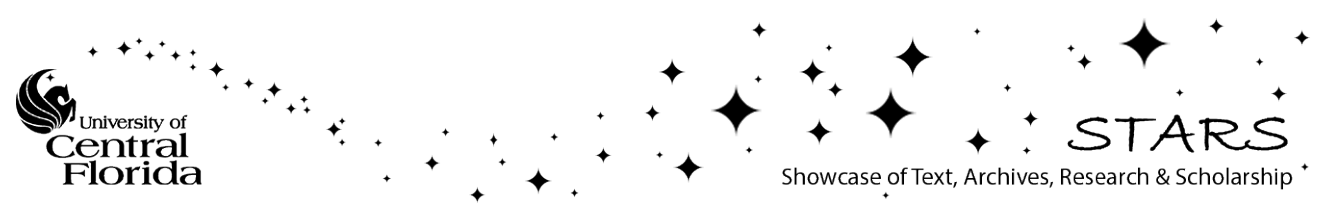




\title{
Non-Erotic Cognitive Distractions During Sexual Activity in Sexual Minority and Heterosexual Young Adults
}

\author{
Katharine Lacefield · Charles Negy
}

Received: 29 April 2010/Revised: 20 May 2011 / Accepted: 22 May 2011 / Published online: 28 July 2011

(C) Springer Science+Business Media, LLC 2011

\begin{abstract}
The present study examined 100 lesbian and gay college students and 100 heterosexual students to determine whether group differences exist in frequency of a range of non-erotic cognitive distractions during sexual activity. Non-erotic cognitive distraction is a descriptive term for both self-evaluative cognitions related to physical performance and body image concerns, as well as additional cognitive distractions (e.g., contracting an STI or emotional concerns) during sexual activity. Participants were matched on gender (96 males and 104 females), age, and ethnicity, and completed questionnaires assessing frequency of non-erotic cognitive distractions during sexual activity, as well as measures of additional variables (trait and body image anxiety, attitudes toward sexual minorities, self-esteem, and religiosity). Results indicated that sexual minorities experienced significantly more cognitive distractions related to body image, physical performance, and STIs during sexual activity than heterosexuals. Regarding gender, men reported more distractions related to STIs than women. Interaction effects were observed between sexual orientation and gender for body image-, disease-, and external/ emotional-based distractions. Implications of these findings are discussed.
\end{abstract}

Keywords Spectatoring - Cognitive distractions . Sexual activity $\cdot$ Sexual orientation

\section{Introduction}

More than 40 years ago, Masters and Johnson (1970) theorized that a key component in sexual dysfunction was "spectatoring,"

K. Lacefield $(\bowtie) \cdot$ C. Negy

Department of Clinical Psychology, University of Central Florida, 4000 Central Florida Blvd., Orlando, FL 32816-1390, USA

e-mail: Katy.Lacefield@knights.ucf.edu a process in which individuals observe themselves from a third party perspective during sexual activity with another person. A critical scrutiny is implied within this observation that impairs the person's ability to enjoy sexual activity as it takes place. Selfmonitoring during sexual behavior presumably creates anxiety, as the person's attention may be diverted from the erotic stimuli, increasing the likelihood of sexual dysfunction. The results from empirical studies based on the theory that anxiety leads to spectatoring, then contributes to sexual dysfunction, have been mixed (Abrahamson, Barlow, Beck, Sakheim, \& Kelly, 1985; Beck \& Barlow, 1986; Sakheim, Barlow, \& Beck, 1984). The possibility that the relation between spectatoring and anxiety may occur in the opposite direction has not been considered in published research. This may be due to the presumption that spectatoring is a critical self-appraisal of one's performance or body, and therefore precedes the anxiety it may cause. Although Masters and Johnson addressed this phenomenon originally in reference to physical performance related to male erectile dysfunction, later research established spectatoring as a concern for women as well, especially regarding body image (Trapnell, Meston, \& Gorzalka, 1997).

Literature following Masters and Johnson expanded the idea of spectatoring or self-monitoring more broadly to include any form of non-erotic cognitive distraction that impairs men's ability to focus and enjoy sexual activity with a partner (Geer \& Fuhr, 1976). Non-erotic cognitive distractions are any form of cognitive distractions that occur during sexual activity that detract from the pleasure of the activity (Purdon \& Holdaway, 2006). More specifically, non-erotic cognitive distraction is a descriptive term for both self-evaluative cognitions related to physical performance and body image concerns, as well as additional cognitive distractions (e.g., contracting an STI or emotional concerns) during sexual activity. A series of experiments examining the effects of non-erotic cognitive distractions on men's physiological sexual arousal resulted in mixed findings, 
wherein such distractions sometimes diminished sexual arousal (Abrahamson et al., 1985), sometimes enhanced arousal (Beck \& Barlow, 1986), and sometimes varied based on experimental condition (Sakheim et al., 1984). Recent work has provided additional support for Barlow's model of sexual functioning, as a relationship between non-erotic cognitive distractions and sexual dysfunction was revealed (Purdon \& Watson, 2011).

The body of literature regarding general cognitive distraction during sexual activity is relatively small and few comparisons of multiple populations have been conducted. Despite that sexual minorities experience sexual dysfunctions (and possibly even more commonly than heterosexuals [Bancroft, Carnes, Janssen, Goodrich, \& Long, 2005]), no study has compared non-erotic cognitive distractions between sexual minorities and heterosexuals. The present research represents a preliminary study on nonerotic cognitive distractions as a function of sexual orientation and gender, and includes potential control variables that have not been considered in previous research that may account for observed for group differences. Thus, in addition to examining type, prevalence, and predictors of cognitive distractions during sexual activity, this study compared lesbian and gay individuals with a relatively comparable sample of heterosexual women and men.

Meana and Nunnink (2006) compared male and female college students on non-erotic cognitive distractions during sexual activity. Specifically, they measured sexual functioning, sexual information, sexual experience, attitudes toward sex, general psychological distress, affect, body image, and sexual satisfaction. They also used the Dove and Wiederman (2000) Cognitive Distraction Scale, which separates cognitive distractions during sexual activity into two distinct categories: distractions related to body image concerns and those related to physical performance. Women reported more overall cognitive distractions during sexual activity than did men. The women also reported significantly more distractions related to a negative body image during sexual activity than men. By contrast, there was no significant difference between men and women regarding the amount of cognitive distraction they reported during sexual activity about their own physical performance. Overall, these results suggest that spectatoring is a problem for females and males, although spectatoring may be more of a problem for females. Moreover, the results of their study helped elucidate predictors of cognitive distractions. For women, psychological distress, body image, and sexual satisfaction were unique predictors of cognitive distraction during sexual activity; in men, negative body image and not being in a relationship predicted higher levels of appearance based distractions, and sexual satisfaction predicted lower levels of appearance based distractions.

Although Meana and Nunnink (2006) assessed only performance- and body image-based cognitive distractions during sexual activity, Purdon and Holdaway (2006) explored the range of content in cognitive distractions, all of which can potentially alter sexual arousal. Purdon and Holdaway collected qualitative data on the range of distracting thoughts as measured by the NonErotic Thought Content Questionnaire (NECT) that was developed for their study. Sexual functioning, sexual satisfaction, and sexual opinions also were measured. Results showed nine categories of distracting thoughts: (1) Intrusion (e.g., getting caught or interrupted during sexual activity); (2) Body Concerns (e.g., appearance or odor); (3) Sexually Transmitted Infections/Pregnancy; (4) Emotional/Relationship; (5) Morality/Guilt/Regret; (6) Dislike of the Sexual Activity; (7) Distracting Thoughts (e.g., work, school); (8) Thoughts of Others; and (9) Performance. Consistent with previous findings, women reported more distracting thoughts, with more frequency, and more associated anxiety than men. These data suggest that non-erotic cognitive distractions during sexual activity may be more concerning for women's sexual functioning than for men's. Once again, more women than men reported distractions in the body image category, but men reported more performance related distraction. Men and women were equally likely to report distractions related to pregnancy or sexually transmitted infection. These findings suggest that there is a broad range of cognitive distractions during sexual activity that extends beyond body image and performance concerns. Similar findings regarding the range of non-erotic cognitive distractions were obtained in a community sample; however, significantly fewer individuals in the community sample reported having no distractions during sexual activity than in an undergraduate sample (Nelson \& Purdon, 2010).

Further evidence that non-erotic cognitive distractions during sexual activity are correlated positively with sexual problems was obtained in a community sample (Nelson \& Purdon, 2010). Women $(N=81)$ and men $(N=72)$ in long-term relationships reported a range of distractions during sexual activity, all types of which were associated with more frequent sexual dysfunction. Consistent with previous findings (Meana \& Nunnink, 2006), distractions reflecting spectatoring behavior were reported such that women were more likely to experience body image concerns during sexual activity and men were more likely to experience performance-based distractions. Unlike data obtained from previous studies, men and women were equally likely to report concerns about the emotional consequences of sexual activity. In this case, the term spectatoring, as intended by Masters and Johnson, may be a misnomer. Distractions that may alter sexual functioning, but do not involve self-focus (e.g., emotional consequences), probably should remain in the category of nonerotic cognitive distractions.

\section{The Current Study}

As the literature reflects, studies on cognitive distractions during sexual activity generally have focused on men more than women (e.g., Abrahamson et al., 1985; Beck \& Barlow, 1986) even though studies that have included women consistently have found 
that women experience cognitive distractions during sex as much as or more than men (e.g., Meana \& Nunnink, 2006; Trapnell et al., 1997). Moreover, although previous studies generally have ignored potential differences across racial and ethnic groups, the absence of diversity in this area of research is even more glaring in the context of sexual orientation. In past studies, sexual minorities were either purposely excluded (e.g., Meston, 2005) or no mention was made with regard to whether sexual minorities were included in the study sample. No published study has examined cognitive distraction during sexual activity with lesbian and gay individuals and, as a result, no information is known about the role of cognitive distraction during sex among sexual minorities. The current study attempted to expand current literature on this topic by comparing relatively homogenous groups, based on sexual orientation and gender, on the types, frequency, and correlates of their cognitive distractions during sexual activity.

In all likelihood, sexual minorities experience many of the same types and qualities of cognitive distractions during sexual activity as do heterosexual people. However, sexual minorities likely experience myriad forms of cognitive distractions that are unique to their sexual orientation and identity development. For example, the cognitive distraction of preoccupation with being discovered in the act of sex by a third-party intruder theoretically has an additional layer of meaning for sexual minorities. In addition to the usual concerns surrounding being caught during sex, such as embarrassment, consequences for violating parents' moral beliefs against premarital sex, and so on, one consequence specific to sexual minorities caught during sex may be having their sexual orientation revealed unintentionally. Both theoretical and empirical literature consistently has delineated the delicate nature and implicational gravity of "being out" for many sexual minorities, such as being rejected by others, being fired from work, and so on (Iwasaki \& Ristock, 2007; Ward \& Winstanley, 2005). As another example, a cognitive distraction that may differ qualitatively for gay men relative to lesbians and heterosexuals is the concern for becoming HIV infected from a sexual experience with another man. Although HIV infection may occur via sexual activity irrespective of sexual orientation and gender, HIV infection is far more likely to occur among men who engage in high risk sex with other men than from other types of sexual activity (i.e., heterosexual sex and lesbian sex; CDC, 2007). Further, struggles with internalized heterosexism (often referred to as homophobia or homonegativity) may also represent a type of cognitive distraction during sex among individuals whose sexual identity as a gay or lesbian is dynamic or for individuals with only a partial awareness of an emerging homosexual orientation. Such individuals may be distracted by thoughts that question their attraction to members of the same sex or the pleasure they derive from engaging in same-sex activity.

Taken together, it seems likely that the types of cognitive distractions during sexual activity may vary more for sexual minorities than for heterosexual people. Additional information about cognitive distractions during sexual activity, particularly among lesbian and gay individuals, may contribute to a better and nuanced understanding of this seemingly common phenomenon. Also, learning more about the similarities and potential dissimilarities in cognitive distractions during sex between sexual minorities and heterosexual people may have clinical implications for therapists who provide treatment for sexual dysfunction to lesbian and gay clients.

Additional variables were included in this study because of their potential relation to the research questions. Participants' trait anxiety was assessed because spectatoring is theorized to be based on anxiety (Masters \& Johnson, 1970). A measure of body image anxiety was included given that previous literature (Conner, Johnson, \& Grogan, 2004; Frederick, Forbes, Grigorian, \& Jarcho, 2007; Morrison, Morrison, \& Sager, 2004) has found that both gender and sexual orientation contribute to differences in appearance-related concerns. Also, attitudes toward sexual minorities were assessed because Rowen and Malcolm (2002) found that an individual's homosexual identity formation may be negatively correlated with internalized homophobia or homonegativity, which may influence sexual dysfunction. A measure of self-esteem was included to assess participants' feelings about themselves, as this has been shown to correlate with sexual dysfunction (Althof et al., 2006). Finally, studies consistently indicate that attitudes and the perceived freedom to engage in sex often are influenced by individuals' interpretation and commitment to their religious beliefs (Murray, Ciarrocchi, \& MurraySwank, 2007). As a result, a measure of religiosity was included in the study. These additional study variables (trait and body image anxiety, attitudes toward sexual minorities, self-esteem, and religiosity) were treated as covariates in comparison analyses and predictor variables in regression analyses.

\section{Hypotheses}

Hypothesis 1 predicted that sexual minority participants would report more frequent non-erotic cognitive distractions during sexual activity compared to heterosexual participants. This hypothesis was made based on the notion that lesbian and gay individuals likely would have higher levels of internalized heterosexism and heightened concerns over being discovered by others for being "gay." Thus, it was expected that their range of cognitive distractions during sex would include thoughts that reflect these lesbian and gay-specific concerns, relative to a comparable group of heterosexuals.

Hypothesis 2 predicted that sexual orientation would interact with gender to produce an effect on cognitive distractions. As discussed earlier, women and men have been found to differ on myriad variables related to body image, distractions during sex, and so on (Meana \& Nunnink, 2006; Purdon \& Holdaway, 2006). Findings related to gender were expected to vary depending on the specific distraction under consideration (e.g., that gay men would report higher distractions related to concern over diseases than the other subgroups). 


\section{Method}

Participants

Approximately 2,000 undergraduate college students at a large public university in the southeastern United States initially participated in this study. Data from 436 participants were excluded based on their reported sexual inactivity during the 3 months prior to study involvement. Of the remaining participants, 200 (104 females, 96 males) were included in analyses, with data from each of the gay and lesbian participants meeting inclusion criteria matched randomly with all eligible heterosexual participants on gender, age, and ethnicity.

Participants' sexual orientation was based on a modified Kinsey 7-point scale (Kinsey, Pomeroy, \& Martin, 1948). Sexual orientation was based on a composite of the four subscales of the modified Kinsey scale. The four subscales pertained to behavior, fantasy, romantic attraction, and self-identification. Individuals included in the "gay" group had a composite score of at least 4.25 out of six, with $85 \%$ of participants in this group obtaining a composite of at least five, and $100 \%$ of participants in this group reporting a self-identification of their sexual orientation of five or six. Individuals included in the "heterosexual" group had a calculated composite score of .5 at most, with 93\% reporting a composite score of 0 , and $100 \%$ of individuals reporting a self-identification of their sexual orientation of 0 .

Lesbians and gay men were matched with a heterosexual participant on gender, race/ethnicity, and age in order to control for these sociodemographic variables. To accomplish the matching process, each gay man and lesbian was included in the study provided that a comparable heterosexual participant—based on gender, ethnicity, and age - could be located from the larger participant pool. Six of the sexual minority participants were not matched on exact age but were matched with a participant within 2 years of their age.

The final sample size used in data analysis was 200 (48 gay men, 48 heterosexual men, 52 lesbians, and 52 heterosexual women). The average age for the sexual minority group of participants was 19.99 years $(\mathrm{SD}=2.57)$ and the average age for the heterosexual group of participants was 19.96 years $(\mathrm{SD}=$ 2.55). Regarding ethnicity, 136 (68\%) of the participants selfidentified as non-Hispanic White, $42(21 \%)$ as Hispanic/Latino/ a, $8(4 \%)$ as African American, and 14 (7\%) as "other." Willing participants were recruited from Psychology courses as well as from the university's Gay, Lesbian, and Bisexual Student Organization (GLBSU). Although no formal records of participation rates were kept, approximately $100 \%$ of those approached at the GLBSU meetings agreed to participate. The authors approximate the participation rate of remaining students vis-à-vis the sample size to be $30 \%$, as 2,000 of 6,000 students enrolled in Introduction to Psychology across three semesters participated in person or online.
Measures

\section{Demographic Questionnaire}

A demographic questionnaire assessed participants' gender, age, ethnicity, current educational status, and parents' educational attainment. Participants were asked to report if they have been sexually active in the past 3 months. Data from participants who had not been sexually active in the past 3 months were not considered for analysis because they were determined to be less likely to recall cognitive distractions they may have experienced during previous sexual activity. Participants were asked to report their age when they first engaged in sexual activity with a partner (defined by any form of genital contact), if they were in a relationship at the time of participation, and, if they were, the length of time they had been in the relationship.

\section{Non-Erotic Cognitive Distraction Questionnaire (NECDQ)}

To assess non-erotic cognitive distractions during sexual activity, all participants initially responded to the NECDQ, a 20-item questionnaire, that was developed by the present authors (see "Appendix"). Part of the NECDQ included ten items extracted from the Body Image Self-Consciousness Scale (Dove \& Wiederman, 2000) in order to assess for body image (five items) and physical performance concerns (five items). Because these items were written originally to apply only to women, the items were modified to be applicable to all participants. The remaining ten items were developed based on categories of distractions delineated by Purdon and Holdaway (2006). These dimension included morality concerns, disease concerns, intrusion, and dislike of the activity. Following a factor analysis of all items (see Table 1), the four factors that emerged were labeled Body Image Concerns (five items), Performance Concerns (four items), External/Emotional Concerns (four items), and Disease Concerns (two items).

Participants indicated their agreement to item statements using a 5-point Likert-type scale ranging from 1 (Never) to 5 (Always). Test-retest reliability $(n=26)$ was .74 for the overall NECDQ score at a 2-week interval. Moreover, as preliminary evidence of the NECDQ's validity, NECDQ subscales on body image, physical performance, and external and emotional concerns correlated significantly and in expected directions with a measure of trait anxiety $(r s=.22-.42)$, body image anxiety $(r s=.20-.52)$, and self-esteem $(r s=-.20$ to -.35 [external/emotional concerns did not correlate significantly with self-esteem]) (all $p \mathrm{~s}<.05)$.

\section{"Trait” Subscale of the State-Trait Anxiety Inventory (STAI)}

The Trait subscale of the STAI is a 20-item measure (Spielberger, Gorsuch, Lushene, Vagg, \& Jacobs, 1983) designed to screen for symptoms of long-standing, chronic anxiety in non-clinical populations. Participants responded to each item by rating how 
Table 1 Factor loadings for exploratory factor analysis with quartimax rotation of non-erotic cognitive distraction scales $(N=260)$

\begin{tabular}{|c|c|c|c|c|}
\hline Scale & $\begin{array}{l}\text { Body } \\
\text { image }\end{array}$ & $\begin{array}{l}\text { Physical } \\
\text { performance }\end{array}$ & $\begin{array}{l}\text { External/ } \\
\text { emotional }\end{array}$ & Disease \\
\hline $\begin{array}{l}\text { It is difficult to enjoy sex because of my concerns over how my body appears } \\
\text { to my partner }\end{array}$ & .83 & .20 & -.01 & .10 \\
\hline During sexual activity, I think about how unattractive my body is & .80 & .23 & .03 & -.08 \\
\hline During sexual activity, I worry that my partner will get turned off by my body & .80 & .16 & .07 & .03 \\
\hline During sexual activity, I worry about how my body looks & .77 & .18 & .00 & -.03 \\
\hline $\begin{array}{l}\text { During sexual activity, I prefer to be in a position such that my partner cannot } \\
\text { see my body }\end{array}$ & .73 & -.05 & .17 & .06 \\
\hline During sexual activity, I worry that my partner will not have an orgasm & .02 & .81 & .00 & .20 \\
\hline During sexual activity, I worry that my partner may not enjoy the activity with me & .31 & .80 & .01 & .08 \\
\hline I worry about whether my actions are satisfying my partner during sexual activity & .30 & .76 & .14 & -.06 \\
\hline During sexual activity, I am distracted by thoughts about my sexual performance & .31 & .73 & .14 & .04 \\
\hline During sexual activity, I worry that I am doing something immoral or sinful & .11 & -.07 & .77 & .17 \\
\hline $\begin{array}{l}\text { During sexual activity, I have concerns that someone may see me or catch me } \\
\text { in the act }\end{array}$ & .04 & .13 & .75 & -.04 \\
\hline During sexual activity, I feel guilty about having sex & .22 & -.03 & .70 & .27 \\
\hline During sexual activity, I worry that someone may overhear what I am doing & -.03 & .28 & .63 & -.15 \\
\hline I worry about getting a STD during sexual activity & .06 & .17 & .09 & .94 \\
\hline I worry about getting AIDS during sexual activity & .04 & .09 & .12 & .94 \\
\hline
\end{tabular}

Note All other factor loadings were $<.35$. Factor loadings appearing in bold indicate items retained for the subscale under which they appear

characteristic each item is of them on a Likert-type scale, ranging from 1 (Almost Never) to 4 (Almost Always). After reversing nine items, individual item scores are summed to obtain an overall composite score, with higher scores suggesting more elevated levels of anxiety.

\section{"Trait" Subscale of the Physical Appearance State and Trait Anxiety Scale (PASTAS)}

To assess participants' anxiety related to attitudes toward their appearance and bodies, all participants completed the trait-version of the PASTAS (Reed, Thompson, Brannick, \& Saco, 1991). The PASTAS contains 16 specific body parts (e.g., buttocks, hips, hands, etc.) to which participants rated the extent to which the parts caused them to feel anxious, concerned, or nervous. Although PASTAS and the NECDQ body image distraction subscale overlap conceptually, PASTAS (unlike the NECDQ subscale) assesses body image anxiety in general (i.e., in non-sexual contexts). Using a 5-point Likert-type scale, response options ranged from 0 (Never) to 4 (Always). High scores indicated more anxiety and a lack of acceptance of one's body.

\section{Heterosexual Attitudes Toward Homosexuality (HATH)}

All participants completed the HATH questionnaire (Larsen, Reed, \& Hoffman, 1980). This is a 20 -item scale assessing attitudes and beliefs in response to gay and lesbian people. Participants responded to items using a 5-point Likert-type scale, with response options ranging from 1 (Strongly Disagree) to 5 (Strongly Agree). Higher scores reflect higher levels of homonegativity. A sample item is "I avoid homosexuals whenever possible." Although HATH typically serves as a measure of homonegativity, for the purposes of this study, it also served as a measure of internalized homophobia for sexual minority participants.

\section{Rosenberg Self-Esteem (RSE) Scale}

All participants completed the RSE scale (Rosenberg, 1989). The RSE scale consists of ten items to which participants respond using a 4-point Likert-type scale, with response options ranging from 1 (Strongly Disagree) to 4 (Strongly Agree). The scale measures two dimensions of self-esteem: self-confidence and selfdeprecation. A composite score is generated by reversing five of the items and then summing across items. Higher scores on the RSE scale are indicative of higher levels of self-esteem.

\section{Religiosity}

To assess participants' commitment to religion and examine its possible correlation with cognitive distraction during sexual activity, they completed ten items developed by Batson, Schoenrade, and Ventis (1993) that assessed participants' level of religiosity. A sample item is "When it comes to religious questions, I feel driven to know the truth." Response options for these items range from 1 (Strongly Disagree) to 5 (Strongly Agree). Higher scores reflect more religiosity. 


\section{Procedure}

Approval by the appropriate Institutional Review Board was obtained prior to data collection. Questionnaire packets were made available to willing participants during Psychology courses, as well as on the university's online research program. Questionnaire packets were also distributed in Gay, Lesbian, Bisexual Student Union meetings (GLBSU). Participants recruited from Psychology courses and online were compensated with extra credit toward their respective courses and participants recruited from GLBSU were compensated with $\$ 5$. No significant differences on any of the four NECDQ scales were observed as a function of data-collection $\operatorname{method}(p s>.05)$. All participants were briefed about the nature of the study within the consent forms. Additional verbal briefing was given prior to the distribution of questionnaire packets in GLBSU. Completion of the questionnaire required approximately $30 \mathrm{~min}$.

\section{Data Analysis}

Primary analyses addressing Hypothesis 1 employed multivariate analysis of variance (MANOVA) to examine main effects of group differences on the four subscales NECDQ. In order to explore variables that might account for any observed differences between sexual minorities and heterosexuals, a series of multivariate analyses of covariance (MANCOVA) were conducted, using additional study variables as covariates. In order to test Hypothesis 2 and determine if interaction effects based on sexual orientation and gender exist on the four subscales of the NECDQ, a MANOVA was conducted, including both sexual orientation and gender as independent variables (IVs). Finally, exploratory standard multiple regression analyses were conducted to identify study variables that predicted the four NECDQ subscales for each participant group, respectively.

\section{Results}

\section{Hypothesis 1}

Table 2 shows the means and SD on the NECDQ scales obtained by participants by sexual orientation and gender. The first hypothesis predicted that lesbian and gay participants would report significantly more non-erotic cognitive distractions during sexual activity than heterosexual participants. To test this hypothesis, a MANOVA was conducted, with sexual orientation as the IV. The four scales of the NECDQ (body image concerns, performance concerns, emotional/external concerns, and disease concerns) served as dependent variables (DVs).

Sexual orientation was associated with a significant effect on non-erotic cognitive distractions using Wilks' Lambda, $F(4$, $193)=8.65, p<.001, \eta_{\mathrm{p}}^{2}=.14$. Univariate tests indicated that sexual minority participants reported significantly more concerns
Table 2 Means and SD for NECDQ subscales as a function of gender and sexual orientation

\begin{tabular}{|c|c|c|c|c|c|c|}
\hline & \multicolumn{3}{|c|}{ Sexual minority } & \multicolumn{3}{|c|}{ Heterosexual } \\
\hline & $M$ & SD & $N$ & $M$ & SD & $N$ \\
\hline \multicolumn{7}{|c|}{ Body image concerns } \\
\hline Men & 2.25 & .96 & 48 & 1.51 & .57 & 48 \\
\hline Women & 2.12 & .80 & 52 & 1.89 & .82 & 52 \\
\hline \multicolumn{7}{|c|}{ Physical performance concerns } \\
\hline Men & 2.34 & .89 & 48 & 2.19 & .88 & 48 \\
\hline Women & 2.50 & .80 & 52 & 1.99 & .79 & 52 \\
\hline \multicolumn{7}{|c|}{ Disease concerns } \\
\hline Men & 2.73 & 1.24 & 48 & 1.67 & .80 & 48 \\
\hline Women & 1.68 & .87 & 52 & 1.58 & .90 & 52 \\
\hline \multicolumn{7}{|c|}{ External/emotional concerns } \\
\hline Men & 1.83 & .74 & 48 & 1.54 & .53 & 48 \\
\hline Women & 1.71 & .51 & 52 & 1.76 & .61 & 52 \\
\hline
\end{tabular}

Note Absolute range for each subscale, 1-5

with their body image than heterosexual participants, $F(1,196)=$ $18.34, p<.001, \eta_{\mathrm{p}}^{2}=.09$, as well as with their sexual performance, $F(1,196)=7.85, p<.05, \eta_{\mathrm{p}}^{2}=.03$. Lesbian and gay participants also expressed more concerns about contracting an STI during sexual activity compared to heterosexual participants, $F(1,196)=$ $18.21, p<.001, \eta_{\mathrm{p}}^{2}=.09$.

A MANOVA was conducted in order to determine whether additional study variables would account for the observed differences on the three NECDQ subscales between the sexual minority and heterosexual participants. Sexual orientation was the IV and additional study variables (HATH, Religiosity, PASTAS, RSE, and STAI) served as DVs. Table 3 shows the means and SD of the five additional study variables as a function of sexual orientation and gender.

Significant group differences were observed on HATH, $F(1$, $198)=83.55, p<.01, \eta_{\mathrm{p}}^{2}=.30$, Religiosity, $F(1,198)=21.76$, $p<.01, \eta_{\mathrm{p}}^{2}=.10$, and PASTAS, $F(1,198)=8.79, p<.01, \eta_{\mathrm{p}}^{2}=$ .04. A series of MANCOVAs were then conducted in which sexual orientation was the IV, the four NECDQ subscales were DVs, and the three additional study variables on which the groups differed (HATH, Religiosity, and PASTAS) were entered as covariates individually and in alternating combinations. The MANCOVAs continued yielding statistically significant sexual minority-heterosexual participant groups differences on the three NECDQ subscales on which differences were observed initially (all $p s<.05$ ), suggesting that none of the additional study variables accounted for sexual minority-heterosexual differences on the NECDQ subscales.

\section{Hypothesis 2}

The second hypothesis predicted that sexual orientation and gender would interact, yielding observed differences on the NECDQ 
Table 3 Means and SD for five study variables as a function of gender and sexual orientation

\begin{tabular}{|c|c|c|c|c|c|c|}
\hline & \multicolumn{3}{|c|}{ Sexual minority } & \multicolumn{3}{|c|}{ Heterosexual } \\
\hline & $M$ & SD & $N$ & $M$ & SD & $N$ \\
\hline \multicolumn{7}{|l|}{$\mathrm{HATH}^{\mathrm{a}}$} \\
\hline Men & 1.81 & .75 & 48 & 2.71 & .59 & 48 \\
\hline Women & 1.79 & .73 & 52 & 2.60 & .53 & 52 \\
\hline \multicolumn{7}{|c|}{ Religiosity $^{\mathrm{a}}$} \\
\hline Men & 2.38 & .68 & 48 & 2.65 & .61 & 48 \\
\hline Women & 2.38 & .86 & 52 & 3.04 & .66 & 52 \\
\hline \multicolumn{7}{|l|}{ PASTAS $^{\mathrm{b}}$} \\
\hline Men & .93 & .73 & 48 & .57 & .55 & 48 \\
\hline Women & 1.19 & .58 & 52 & 1.02 & .51 & 52 \\
\hline \multicolumn{7}{|l|}{$\operatorname{RSE}^{\mathrm{c}}$} \\
\hline Men & 3.13 & .67 & 48 & 3.26 & .54 & 48 \\
\hline Women & 3.10 & .54 & 52 & 3.11 & .58 & 52 \\
\hline \multicolumn{7}{|l|}{$\mathrm{STAI}^{\mathrm{c}}$} \\
\hline Men & 2.07 & .52 & 48 & 1.91 & .52 & 48 \\
\hline Women & 2.16 & .44 & 52 & 2.09 & .57 & 52 \\
\hline
\end{tabular}

a Absolute range, 1-5

b Absolute range, $0-4$

c Absolute range, 1-4

subscales. To test this hypothesis, a 2 (gender) $\times 2$ (sexual orientation) MANOVA was conducted for the four scales of the NECDQ (body image concerns, performance concerns, emotional/external concerns, and disease concerns). There was a significant effect associated with the interaction between gender and sexual orientation, $F(4,193)=6.26, p<.001, \eta_{\mathrm{p}}^{2}=.12$. Univariate tests indicated there was a significant sexual orientation $\times$ gender interaction on body image concerns, $F(1,196)=$ $5.02, p<.05, \eta_{\mathrm{p}}^{2}=.03$, disease concerns, $F(1,196)=12.21$, $p<.01, \eta_{\mathrm{p}}^{2}=.06$, and external/emotional consequences, $F(1$, $196)=3.98, p<.05, \eta_{\mathrm{p}}^{2}=.02$. Heterosexual women reported more body image-based distractions during sexual activity than heterosexual men. By contrast, among sexual minority participants, men reported more body image-based distractions than women. Although heterosexual men reported higher levels of disease-based distractions than heterosexual women, the difference between gay men's and lesbians' disease-based distractions was more conspicuous, with gay men's scores being higher than lesbians' scores. Heterosexual women reported more external/emotional-based distractions than heterosexual men, whereas gay men reported more external/emotional-based distractions than lesbians.

\section{Ancillary Regression Analyses for Five Study Variables}

Standard multiple regressions were performed separately by participant group, predicting each of the four NECDQ subscale from the following study variables: attitudes toward sexual minorities, religiosity, self-esteem, trait anxiety, and body image anxiety
(PASTAS) for each group of participants (i.e., gay men, lesbians, heterosexual men, and heterosexual women). Examination of indicators suggestive of problems with collinearity among the predictor variables (e.g., small tolerance values, beta coefficients $>1$, relatively large variance inflation factors [Tabachnick \& Fidell, 2001]) showed no indication of apparent difficulties of collinearity.

When the five study variables were entered simultaneously as predictor variables, the variables conjointly predicted body image-based distractions and disease-based distractions for gay men, multiple $R^{2}=.33, F(5,42)=4.12, p<.01$, and multiple $R^{2}=.30, F(5,42)=3.60, p<.05$, respectively. The variable that individually contributed to the prediction of body imagebased distractions in gay men was body image anxiety $(B=.40$; $t=2.68, p<.05$ ). The variables that contributed to the prediction of disease-based concerns in gay men were: homonegativity $(B=.35 ; t=2.18, p<.05)$ and body image anxiety $(B=.43$; $t=2.84, p<.01)$. Overall, the five IVs conjointly predicted body image-based distractions for lesbians, multiple $R^{2}=.32, F(5$, $46)=3.72, p<.01$; however, no individual variables achieved statistical significance. Overall, the five predictor variables conjointly predicted body image-based distractions, multiple $R^{2}=$ $.28, F(5,42)=3.33, p<.05$, and physical performance-based concerns, multiple $R^{2}=.30, F(5,42)=3.67, p<.01$, for heterosexual men. Though no variable individually contributed to the prediction of physical performance-based distractions, the variable that individually contributed to the prediction of body imagebased distractions in heterosexual men was trait anxiety $(B=.47$; $t=2.47, p<.05)$. Overall, the predictor variables conjointly predicted body image-based distractions for heterosexual women, multiple $R^{2}=.25, F(5,46)=3.12, p<.05$. The variable that individually contributed to the prediction of body image-based distractions in heterosexual women was body dissatisfaction $(B=$ $.36 ; t=2.19, p<.05)$. All remaining multiple regressions for the four groups of participants failed to achieve statistical significance.

\section{Discussion}

Our study was an initial investigation into non-erotic cognitive distractions among sexual minorities and heterosexuals. The first hypothesis predicted that lesbian and gay participants would report significantly more non-erotic cognitive distractions during sexual activity than heterosexual participants. This hypothesis was supported. Although findings from all groups were suggestive of relatively infrequent distractions, lesbian and gay individuals reported significantly more non-erotic cognitive distractions related to body image, performance, and disease concerns than their heterosexual counterparts. Two of the three NECDQ distraction subscales on which sexual minorities differed from heterosexuals (i.e., body image- and physical performance-based distractions) represent the phenomenon of spectatoring during 
sexual activity. Those types of distractions also reflect concerns about how they are being perceived by their partners in terms of both appearances and ability to perform sexually. Thus, it seems that, relative to heterosexuals, sexual minorities may experience, in various degrees, heightened levels of inadequacy during sexual activity.

The second hypothesis predicted that sexual orientation and gender would interact, yielding observed differences on the NECDQ subscales. This hypothesis was supported. The interaction of sexual orientation and gender affected body image-, external/emotional-, and disease-based distractions. Discussion of results pertaining to both hypotheses is presented for each subscale of the NECDQ.

With regard to body image distractions, lesbians and gay men reported more frequent distractions than heterosexual men and women. Contrary to previous research (e.g., Meana \& Nunnink, 2006; Purdon \& Holdaway, 2006), findings of our study did not reveal significant gender differences for body image distractions. In light of this, examination of the interactions between sexual orientation and gender helped to elucidate findings. Among lesbian and gay participants, gay men expressed more body image distractions and anxiety than lesbians. Among heterosexual participants, women expressed more body image distractions than men. It seems that preoccupations with one's appearance-in a comparative sense - are the province of heterosexual women and gay men. Although the explanation for these discrepant findings is unknown, Siever (1994) has proposed that heterosexual women and gay men both desire to appeal to men and, therefore, are concerned about their appearance more than heterosexual men or lesbians. More recent findings (Peplau et al., 2009), however, suggest that lesbians share body image concerns similar to those of gay men and heterosexual women.

Overall, sexual minorities reported greater frequency of physical performance concerns than heterosexual participants. Specifically, lesbians reported greater frequency of this type of distraction than heterosexual women. This finding seems inconsistent with that of a recent study in which, unlike heterosexual women, lesbians' degree of anxiety did not correlate with their sexual functioning (Beaber \& Werner, 2009). Perhaps it is the case that, despite increased frequency of distractions related to physical performance, lesbians are able to function sexually, despite the anxiety associated with such distractions.

Although sexual minorities reported greater frequency of distractions related to disease concerns compared to heterosexuals, analysis of the interaction between sexual orientation and gender revealed that, on average, gay men expressed relatively higher levels of distractions related to their concerns over contracting a sexually related illness. Some of this concern, particularly among gay men, is valid given the relatively higher frequencies of STIs within the gay community. For example, men who have sex with men are estimated to account for $2 \%$ of the population, yet they constitute more than half of all individuals living with HIV in the United States (CDC, 2010).

Although no main effect was observed for differences between groups based on sexual orientation for external/emotional-based distractions, a significant interaction between sexual orientation and gender was obtained on this subscale. Specifically, heterosexual women reported more distractions related to external/emotional concerns, whereas gay men reported more external/emotion-based distractions than lesbians. In the United States, among heterosexuals, women generally have less freedom to be sexually active (particularly outside of marriage) than men (Crawford \& Popp, 2003; Greaves, 2001; Greene \& Faulkner, 2005); thus, they may be more likely than men to have concerns about being discovered engaging in sexual activity. By contrast, in the United States, there is less acceptance and more condemnation of male homosexuality than female homosexuality (Kerns \& Fine, 2005). It is speculated that these findings are a result of the discrepant patterns of social acceptance of sexual activity across the lines of gender and sexual orientation.

An attempt was made to determine if additional study variables may have accounted for the obtained sexual orientation differences in cognitive distractions during sexual activity. Despite that sexual minority and heterosexual participants differed significantly on three of these variables included in this study (i.e., homonegativity, religiosity, and body image anxiety as measured by PASTAS), the sexual orientation differences on the three categories of distractions remained statistically significant after controlling for the extra-study variables. Either the sexual orientation differences on cognitive distractions are robust phenomena or other variables not included in this study might account for the differences.

Results from the regression analyses suggested several directions for future research. Body dissatisfaction significantly predicted body image distractions among gay men and heterosexual women, as well as disease-related distractions among gay men. Body dissatisfaction significantly predicted physical performance distractions among heterosexual men. Aside from another similarity between gay men and heterosexual women, body dissatisfaction clearly represents a source of distress and distraction for various young adults during sexual activity. Perhaps the more noteworthy finding was that homonegativity significantly predicted disease-related distractions among gay men. It is not uncommon for gay men to have internalized some level of negative social attitudes about homosexuality (Smolenski, Ross, Risser, \& Rosser, 2009). Further, the general notion still exists that HIV and AIDS are gay men's illnesses, despite that those conditions can afflict individuals irrespective of sexual orientation. Although HIV and other STIs clearly warrant concern and precaution among those who are sexually active, these findings suggest that internalized homonegativity among gay men may exacerbate the preoccupation over acquisition of a 
sexually-related illness. Likewise, preoccupations over STIs may exacerbate internalized homonegativity.

\section{Limitations of the Study}

Several limitations of this study warrant noting. Participants in this study were young adults attending college. Given that the majority of adults in the United States do not graduate from a university, these findings may not generalize to adults in the community. Also, the participation prerequisite of having engaged in sex during the last 3 months may have excluded participants who differed than the current sample of participants in various ways, thus further reducing the generalizability of these findings. As an example, it is possible that those excluded for sexual inactivity during the past 3 months may have been more likely to have been affected by cognitive distractions during sexual activity, leading to sexual avoidance for the past 3 months or more. Also, the relatively low endorsement of distractions during sex in this sample created a restricted range of data which may obfuscate statistically significant differences with meaningful clinical information. As an additional potential limitation, the authors note that none of the scales used in this study have been validated with sexual minorities. Finally, controlling for additional variables such as body mass index (BMI), neuroticism, degree of "out"-ness of gay participants, condom use, and participants' satisfaction with their current sex life may have clarified variables underlying observed group differences, but were not measured in this study.

\section{Conclusions and Implications}

Collectively, the findings from this study suggest that sexual minorities experience a range of cognitive distractions during sexual activity comparable to heterosexuals. They appeared, however, to experience more distractions related to internalized homonegativity (particularly among gay men) and elevated distractions related to STI concerns, compared to heterosexuals. The implicit feelings of inadequacy based on sexual minorities' elevated levels of distraction during sexual activity have potential implications for treatment of sexual dysfunction and, at minimum, may help to improve in vivo sexual pleasure experienced by gay men and lesbians. First, consistent with previous studies, in order to decrease concerns related to practical distractions such as contracting an illness during sex or being interrupted, clinicians may provide psychoeducation related to safer sex practices (Purdon \& Holdaway, 2006). The current authors speculate but do not know with certainty that perhaps gay men reported more frequent concerns related to contracting an illness, at least in part, due to inconsistent condom use. If sexual minorities take steps to minimize the potential of contracting an illness through sexual contact, they probably will be less likely to experience related distractions, thus reducing dysfunction and related anxiety.
Additionally, the present findings may aid clinicians by sensitizing them to the potential impact homonegativity and body dissatisfaction have on the psychological well-being of gay clients. Even in the most intimate setting with a consenting samesex partner, some sexual minorities may be affected by social biases related to homosexuality and be unable to manage insecurities about their physical appearance and how well they perform sexually at the expense of their sexual enjoyment. Although these data were not able clarify why heterosexual and gay participants differed on several dimensions of distractions, it may behoove therapists to explore these concerns with sexual minority clients if such concerns are presented by sexual minority clients or appear relevant to their presenting problems. Understanding underlying variables contributing to these distractions may be an integral cognitive therapeutic component in reducing their frequency and related anxiety. Last, future research may consider examining more closely the relation between non-erotic cognitive distractions during sexual activity and sexual dysfunction.

\section{Appendix}

Non-Erotic Cognitive Distractions Questionnaire

People often have thoughts during their sexual encounters that detract from the quality of the experience. Please respond to the following items in reference to the last few times you have engaged in sexual activity.

1. During sexual activity, I worry about how my body looks.

$\begin{array}{lllll}1 & 2 & 3 & 4 & 5 \\ \text { Never } & \text { Rarely } & \text { Sometimes } & \text { Often } & \text { Always }\end{array}$

2. It is difficult to enjoy sex because of my concerns over how my body appears to my partner.

3. During sexual activity, I think about how unattractive my body is.

4. During sexual activity, I worry that my partner will get turned off by seeing my body without clothes.

5. During sexual activity, I prefer to be in a position such that my partner cannot see my body.

6. During sexual activity, I worry that my partner may not enjoy the activity with me.

7. During sexual activity, I worry that my partner will not have an orgasm.

8. I worry about whether my actions are satisfying my partner during sexual activity.

9. During sexual activity, I am distracted by thoughts about my sexual performance.

10. During sexual activity, I have concerns that someone may see or catch me in the act. 
11. I worry about getting a sexually transmitted disease (STD) during sexual activity.

12. I worry about getting AIDS during sexual activity.

13. During sexual activity, I worry that someone may overhear what I am doing.

14. During sexual activity, I feel guilty about having sex.

15. During sexual activity, I feel like I am doing something immoral or sinful.

\section{References}

Abrahamson, D. J., Barlow, D. H., Beck, J. G., Sakheim, D. K., \& Kelly, J. P. (1985). The effects of attentional focus and partner responsiveness on sexual responding: Replication and extension. Archives of Sexual Behavior, 14, 361-371.

Althof, S. E., O’Leary, M. P., Cappelleri, J.C., Glina, S., King, R., Tseng, L., et al. (2006). Self-esteem, confidence, and relationships in men treated with sildenafil citrate for erectile dysfunction. Journal of General Internal Medicine, 21, 1069-1074.

Bancroft, J., Carnes, L., Janssen, E., Goodrich, D., \& Long, J. S. (2005). Erectile and ejaculatory problems in gay and heterosexual men. Archives of Sexual Behavior, 34, 285-297.

Batson, C. D., Schoenrade, P., \& Ventis, W. L. (1993). Religion and the individual: A socio-psychological perspective. New York: Oxford University Press.

Beaber, T. E., \& Werner, P. D. (2009). The relationship between anxiety and sexual functioning in lesbians and heterosexual women. Journal of Homosexuality, 56, 639-654.

Beck, J. G., \& Barlow, D. H. (1986). The effects of anxiety and attentional focus on sexual responding: I. Physiological patterns in erectile dysfunction. Behaviour Research and Therapy, 24, 9-17.

Center for Disease Control and Prevention. (2010). HIV among gay, bisexual and other men who have sex with men (MSM). Retrieved from http://www.cdc.gov/hiv/topics/msm/index.htm.

Centers for Disease Control and Prevention. (2007). HIV/AIDS and men who have sex with men (MSM). Retrieved from http://www.cdc. gov/hiv/topics/msm/.

Conner, M., Johnson, C., \& Grogan, S. (2004). Gender, sexuality, body image, and eating behaviours. Journal of Health Psychology, 9, 505-515.

Crawford, M., \& Popp, D. (2003). Sexual double standards: A review and methodological critique of two decades of research. Journal of Sex Research, 40, 13-26.

Dove, N. L., \& Wiederman, M. W. (2000). Cognitive distraction and women's sexual functioning. Journal of Sex and Marital Therapy, 26, 67-78.

Frederick, D. A., Forbes, G. B., Grigorian, K. E., \& Jarcho, J. M. (2007). The UCLA Body Project I: Gender and ethnic differences in selfobjectification and body satisfaction among 2,206 undergraduates. Sex Roles, 57, 317-327.

Geer, J. H., \& Fuhr, R. (1976). Cognitive factors in sexual arousal: The role of distraction. Journal of Consulting and Clinical Psychology, 44, 238-243.

Greaves, R. M. (2001). The social construction of sexual interaction in heterosexual relationships: A qualitative analysis. Dissertation Abstracts International: Section A: Humanities and Social Sciencs, 61(11-A), 4565.

Greene, K., \& Faulkner, S. (2005). Gender, belief in the sexual double standard, and sexual talk in heterosexual dating relationships. Sex Roles, 53, 239-251.

Iwasaki, Y., \& Ristock, J. L. (2007). The nature of stress experienced by lesbians and gay men. Anxiety, Stress \& Coping, 2, 299-319.
Kerns, J. G., \& Fine, M. A. (2005). The relation between gender and negative attitudes toward gay men and lesbians: Do gender role attitudes mediate this relation? Sex Roles, 31, 297-307.

Kinsey, A. C., Pomeroy, W. B., \& Martin, C. E. (1948). Sexual behavior in the human male. Philadelphia: W. B. Saunders.

Larsen, K. S., Reed, M., \& Hoffman, S. (1980). Attitudes of heterosexuals toward homosexuality: A Likert-type scale and construct validity. Journal of Sex Research, 16, 245-257.

Masters, W. H., \& Johnson, V. E. (1970). Human sexual inadequacy. Boston: Little, Brown and Company.

Meana, M., \& Nunnink, S. E. (2006). Gender differences in the content of cognitive distraction during sex. Journal of Sex Research, 43, $59-67$.

Meston, C. M. (2005). The effects of state and trait self-focused attention on sexual arousal in sexually functional and dysfunctional women. Behaviour Research and Therapy, 44, 1-19.

Morrison, M., Morrison, T., \& Sager, C. (2004). Does body satisfaction differ between gay men and lesbian women and heterosexual men and women? A meta-analytic review. Body Image, 1, 127-138.

Murray, K. M., Ciarrocchi, J. W., \& Murray-Swank, N. A. (2007). Spirituality, religiosity, shame and guilt as predictors of sexual attitudes and experiences. Journal of Psychology and Theology, 35, 222234.

Nelson, A. L., \& Purdon, C. (2010). Non-erotic thoughts, attentional focus, and sexual problems in a community sample. Archives of Sexual Behavior, 40, 395-406.

Peplau, L. A., Frederick, D. A., Yee, C., Maisel, N., Lever, J., \& Ghavami, N. (2009). Body image satisfaction in heterosexual, gay, and lesbian adults. Archives of Sexual Behavior, 38, 713-725.

Purdon, C., \& Holdaway, L. (2006). Non-erotic thoughts: Content and relation to sexual functioning and sexual satisfaction. Journal of Sex Research, 43, 154-162.

Purdon, C., \& Watson, C. (2011). Non-erotic thoughts and sexual functioning. Archives of Sexual Behavior. doi:10.1007/s10508-0119755-Z.

Reed, D. L., Thompson, J. K., Brannick, M. T., \& Saco, W. P. (1991). Development and validation of the Physical Appearance State and Trait Anxiety Scale (PASTAS). Journal of Anxiety Disorders, 5, 323-332.

Rosenberg, M. (1989). Society and the adolescent self-image (revised ed.). Middletown, CT: Wesleyan University Press.

Rowen, C. J., \& Malcolm, J. P. (2002). Correlates of internalized homophobia and homosexual identity formation in a sample of gay men. Journal of Homosexuality, 43, 77-92.

Sakheim, D. K., Barlow, D. H., \& Beck, J. G. (1984). The effect of an increased awareness of erectile cues on sexual arousal. Behaviour Research and Therapy, 22, 151-158.

Siever, M. D. (1994). Sexual orientation and gender as factors in socioculturally acquired vulnerability to body dissatisfaction and eating disorders. Journal of Consulting and Clinical Psychology, 62, 252260.

Smolenski, D. J., Ross, M. W., Risser, J. M. H., \& Rosser, B. R. S. (2009). Sexual compulsivity and high-risk sex among Latino men: The role of internalized homonegativity and gay organizations. AIDS Care, $21,42-49$.

Spielberger, C. D., Gorsuch, R. L., Lushene, R., Vagg, P. R., \& Jacobs, G. A. (1983). Manual of the State-Trait Anxiety Inventory. Palo Alto, CA: Consulting Psychologists Press.

Tabachnick, B. G., \& Fidell, L. S. (2001). Using multivariate statistics. Boston: Pearson/Allyn \& Bacon.

Trapnell, P. D., Meston, C. M., \& Gorzalka, B. B. (1997). Spectatoring and the relationship between body image and sexual experience: Self-focus or self-valence? Journal of Sex Research, 34, 267-278.

Ward, J., \& Winstanley, D. (2005). Coming out at work: Performativity and the recognition and renegotiation of identity. Sociological Review, 53, 447-475. 